ARTICLE

\title{
Antiretroviral therapy for the management of HIV in children
}

\author{
L Frigati, MB ChB, DCH, Dip HIV, MMed, FCPaed (SA), MSc TMIH (UK), Cert ID (SA) Paed; \\ M F Cotton, MB ChB, DCH, FCPaed (SA), PhD; H Rabie, MB ChB, MMed, FCPaed (SA), MSc ID
}

Division of Paediatric Infectious Diseases, Department of Paediatrics and Child Health, Faculty of Medicine and Health Sciences, Tygerberg Academic Hospital and Stellenbosch University, Cape Town, South Africa

Corresponding author: L Frigati (frigati@sun.ac.za)

\begin{abstract}
Since 2004, when antiretroviral therapy (ART) was first available to children through the National Department of Health, there has been significant progress in preventing and treating paediatric HIV. Large cohort studies and prospective trials confirmed that young children require early diagnosis with rapid access to ART regardless of CD4+ lymphocyte count. Studies also confirmed the importance of ritonavir-boosted protease inhibitors during therapy, regardless of prior nevirapine exposure. As prevention strengthens and the paediatric population ages, the goal posts are shifting towards even earlier diagnosis, targeting newborn infants on the first day of life and also the perinatally infected adolescent.

There is an increasing focus on the long-term health, social, developmental and scholastic outcomes of HIV-infected children. Clinicians require new skills to assist children with transition into adulthood. In this article we focus on the care of infants and children.

S Afr Med J 2014;104(12):898. DOI:10.7196/SAMJ.9091
\end{abstract}

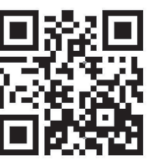

Guidance on the indications for starting antiretroviral therapy (ART) and the preferred initial drugs has evolved substantially over the past 15 years. These changes were the result of a better understanding of the rate of disease progression and the high early morbidity and mortality. There is now a better appreciation of the long-term implications of early therapy and how to sequence the available drugs.

\section{Which children need ART?}

The 2013 World Health Organization (WHO) and South African (SA) ART guidelines ${ }^{[1,2]}$ recommend starting ART for all children $<5$ years of age and fast-tracking those who are very young and have severe disease (Table 1).

In the absence of ART, the majority of infants progress to AIDS and death within 18 months. ${ }^{[3]}$ The strategy for ART initiation in all infants was studied in the Children with HIV Early Antiretroviral (CHER) trial. ${ }^{[4]}$ Early ART was compared with a deferred approach in infants

Table 1. Indications for starting antiretroviral therapy and fast-tracking

\begin{tabular}{lll}
\hline Age & Indication & Fast-tracking \\
\hline Birth - 5 years & All children & Infants $<1$ year of age \\
& & Hospitalised children \\
& MDR- or XDR-TB \\
& WHO stage $3 / 4$ disease \\
& Severe immune suppression \\
& & WHO stage $3 / 4$ disease \\
5 - 15 years & WHO stage $3 / 4$ & MDR- or XDR-TB \\
& disease, or $\mathrm{CD} 4^{+}$ & $\mathrm{CD} 4^{+}<200$ cells $/ \mu \mathrm{L}$ or \\
& $<350$ cells $/ \mu \mathrm{L}^{*}$ & $\mathrm{CD} 4^{+}<15 \%$ \\
& &
\end{tabular}

$<12$ weeks of age and with a baseline $\mathrm{CD} 4^{+} \geq 25 \%$. Infants entered the trial at a median of 7 weeks of age. Children on early therapy had a significant reduction in mortality and HIV progression. ${ }^{[4]}$ Some notable advantages were a reduction in tuberculosis (TB) incidence ${ }^{[4]}$ and an improvement in developmental outcomes. ${ }^{[5]}$ Griffiths Mental Development Scales scores were significantly higher for children who started early treatment ( 106.3 v. $100.1 ; p=0.02)$. Early treatment was also associated with higher locomotor scores $(97.7$ v. $88.9 ; p<0.001) .{ }^{[5]}$

In a subsequent retrospective study of infants who started therapy by 8 weeks of age under programmatic conditions, $62 \%$ already had advanced disease, indicating that more should be done to diagnose and treat infants even earlier. ${ }^{[6]}$ Very early therapy in the neonatal period is possible despite challenges in drug options and dosing. The only drugs that have been studied extensively in term and preterm infants are zidovudine (ZDV) and lamivudine (3TC). One study of HIV-infected Canadian infants that initiated therapy within 72 hours $^{[7]}$ and the case of the Mississippi baby suggest that very early therapy may limit the HIV reservoir. ${ }^{[8]}$

The evidence for starting children between 2 and 5 years of age is less clear. ${ }^{[9]}$ The current recommendations are only partially based on evidence of clinical benefit, but are also an attempt to simplify complex operational and programmatic issues. The Pediatric Randomized Early v. Deferred Initiation in Cambodia and Thailand (PREDICT) trial enrolled children of 1 - 12 years of age without AIDS-defining illnesses and relatively high $\mathrm{CD}^{+}$counts. Outcomes with deferring ART were equivalent to immediate ART. ${ }^{[10]}$ There was no significant difference with regard to viral suppression, CD4 ${ }^{+}$ percentage after ART initiation or toxicity. Of note, intelligence quotient did not differ 3 years after study entry, regardless of ART strategy. ${ }^{[11]}$ However, it is likely that the neurological benefit of early ART was already forfeited in this group. It is important to note that the definition of HIV-associated encephalopathy used in both the $\mathrm{CHER}^{[4]}$ and PREDICT ${ }^{[11]}$ trials did not include less severe manifestations of neurodevelopmental dysfunction. 


\section{Rationale for the current national first regimen}

Initially, the ART programme used stavudine $(\mathrm{d} 4 \mathrm{~T})$ as a first-line nucleoside reverse transcriptase inhibitor (NRTI). d4T is easy to use, has very few initial complications and is inexpensive. Serious late complications such as lipoatrophy and lactic acidosis led to replacement by abacavir (ABC) for children and tenofovir (TDF) for adults. ${ }^{[2]} \mathrm{ABC}$ has an excellent short- and long-term sideeffect profile and requires only clinical monitoring soon after initiation. ${ }^{[12]}$ The Paediatric European Network for Treatment of AIDS (PENTA) 5 study clearly showed that ABC plus 3TC combined with unboosted nelfinavir (NFV) performed better than ZDV plus $3 \mathrm{TC}$ or ZDV plus ABC with unboosted-NFV ${ }^{[12]} \mathrm{ABC}$ as first line may also select for more 'manageable' resistance patterns in failing children. However, since switching to ABC plus 3TC as the first-line NRTI backbone in children, there are concerns about its efficacy in SA children. ${ }^{[13]}$ This was highlighted in a retrospective study with a number of confounders, including the relative lack of rigor of data collection under programmatic conditions and rifampicin co-treatment for children with $\mathrm{TB}$ on lopinavir/ritonavir (LPV/r)-based regimens. ${ }^{[14]}$ More recently, the randomised Pharmacokinetics and Adherence/ Acceptability of Simple Antiretroviral Regimens (CHAPAS-3) study showed that $\mathrm{ABC}$ performed as well as both $\mathrm{d} 4 \mathrm{~T}$ and $\mathrm{ZDV}$ when combined with 3TC as NRTI backbone with a non-NRTI (NNRTI). ${ }^{[15]}$

$\mathrm{ABC}$ hypersensitivity reaction (HSR) is associated with $H L A{ }^{\star} B 5701, H L A-D R 7$ and HLA-DQ3 genotypes. ${ }^{[16]} H L A{ }^{\star} B 5701$ is the most common risk factor. During the Antiretroviral Research for Watoto (ARROW) study of more than 1200 HIV-infected infants from Uganda and Zimbabwe, HSR occurred in $0.2 \%$ of children. ${ }^{[17]}$ The diagnosis is clinical and therapy should not be interrupted if the case definition is not met. After interruption for HSR, ABC cannot be re-initiated.

Children still receiving first-line $\mathrm{d} 4 \mathrm{~T}$ should be switched to $\mathrm{ABC}$ to avoid lipoatrophy if the viral load is undetectable. Children on

\section{Table 2. Recommended first regimen}

\begin{tabular}{|c|c|c|}
\hline Age & Regimen & $\begin{array}{l}\text { When to consider } \\
\text { switching in failing } \\
\text { children }\end{array}$ \\
\hline $\begin{array}{l}\text { All infants and } \\
\text { children } \\
<3 \text { years (or <10 kg) }\end{array}$ & $\mathrm{ABC}+3 \mathrm{TC}+\mathrm{LPV} / \mathrm{r}$ & $\begin{array}{l}\text { Established on ART } \\
>4 \text { - } 6 \text { months } \\
\text { and viral load }>5000 \\
\text { copies/mL on two } \\
\text { occasions } 2 \text { - } 3 \text { months } \\
\text { apart }\end{array}$ \\
\hline $\begin{array}{l}\text { Children } \\
\geq 3 \text { years (or } \geq 10 \mathrm{~kg} \text { ) }\end{array}$ & $\mathrm{ABC}+3 \mathrm{TC}+\mathrm{EFV}$ & $\begin{array}{l}\text { Established on ART } \\
>4 \text { - } 6 \text { months } \\
\text { and viral load } \\
>1000 \text { copies } / \mathrm{mL} \text { on } \\
\text { two occasions } 2-3 \\
\text { months apart }\end{array}$ \\
\hline $\begin{array}{l}\text { Currently on } \mathrm{d} 4 \mathrm{~T} \text { - } \\
\text { based regimen }\end{array}$ & $\begin{array}{l}\text { Change } \mathrm{d} 4 \mathrm{~T} \text { to } \mathrm{ABC} \text { if } \\
\text { viral load is } \\
\text { undetectable }\end{array}$ & $\begin{array}{l}\text { If viral load }>1000 \\
\text { copies } / \mathrm{mL} \text {, manage as } \\
\text { treatment failure } \\
\text { If viral load } 50 \text { - } 1000 \\
\text { copies } / \mathrm{mL} \text { - consult } \\
\text { an expert }\end{array}$ \\
\hline
\end{tabular}

efavirenz (EFV) with a viral load of $>1000$ copies $/ \mathrm{mL}$ and those on $\mathrm{LPV} / \mathrm{r}$ with a viral load of $>5000$ copies $/ \mathrm{mL}$, should be managed as for treatment failure. When the viral load is detectable, but below these thresholds for regimen switching, a single drug substitution with $\mathrm{ABC}$ should not be done. If considered essential, consult an experienced clinician (Table 2).

TDF is licensed in the USA from the age of 2 years and is a first-line treatment recommendation by the WHO ${ }^{[1]}$ However, as TDF is only licensed from 18 years in SA and there are no available appropriate formulations, we currently do not support its routine use. Selected children with specific indications such as hepatitis B should be offered TDF, but bone and renal toxicity must be carefully monitored. The serum creatinine must be measured and the glomerular filtration rate calculated using an age-appropriate formula. When possible, bone density monitoring should be offered.

As the third drug in first-line ART, the protease inhibitor (PI) $\mathrm{LPV} / \mathrm{r}$ is superior to nevirapine (NVP) in children $<3$ years of age, regardless of past NVP exposure. ${ }^{[18]}$ In children started on ART $>3$ years of age, the PENPACT- 1 study showed that, after 4 years on ART, viral suppression and $\mathrm{CD}^{+}$count were similar on NNRTI and PI-based ART. ${ }^{[19]}$ Of note, the PI most commonly used was unboosted nelfinavir, an unacceptable choice given current knowledge. LPV/r solution is not palatable and refusal of the drug is common in children. Also, there is concern about longer-term metabolic complications and cost. Co-treatment of TB requires additional ritonavir (RTV) boosting, taken separately from LPV/r. Switching suppressed children from LPV/r to NVP for those $<3$ years or EFV for those $>3$ years resulted in sustained viral suppression in the Nevirapine Resistance Study (NEVEREST) studies. ${ }^{[20,21]}$ Although switching to EFV in children $>3$ years and to NVP in those $<3$ years was successful in some instances, currently infants failing prevention of mother-to-child transmission (PMTCT) have prolonged NNRTI exposure for at least 6 weeks, rather than only a single dose as in NEVEREST, thus increasing the risk of subsequent significant NNRTI resistance. In NEVEREST-2, failure occurred more often in children with baseline NNRTI resistance (plasma RNA >1 000 copies $/ \mathrm{mL}$ ) when switched to NVP than in those remaining on LPV/r (22\% v. 10\%; $p=0.009) .{ }^{[19]}$ Although routine switching from LPV/r to NNRTI is not part of the current guidelines, it can be considered on an individual basis in suppressed older children with intolerance or toxicity or in those who would benefit from EFV during TB treatment, but careful viral load monitoring soon after the switch is essential.

EFV for first-line therapy in children $>3$ years of age and weighing $10 \mathrm{~kg}$ is still recommended, despite concern about prior exposure to NVP through PMTCT. Careful virological monitoring in children infected despite PMTCT is essential. The US Food and Drug Administration (FDA) recently approved EFV in children $<3$ years and weighing $<10 \mathrm{~kg}$. However, this is not thought to be a safe approach given our current PMTCT strategy.

\section{Once-daily dosing}

To simplify ART, once-daily dosing of ABC and 3TC was studied. Both can be given once daily from $20 \mathrm{~kg}$ and 3 years of age, although some experts recommend daily $3 \mathrm{TC}$ only from $25 \mathrm{~kg} \cdot{ }^{[22-24]}$ The latest weight-based therapy chart allows for this (available on the SA HIV Clinicians Society website: http://www.sahivsoc.org). The availability of the lower-dose ABC tablets $(60 \mathrm{mg})$ and $\mathrm{ABC} / 3 \mathrm{TC}$ $(600 / 300 \mathrm{mg})$ fixed-dose combination allows for simplification and reduction of pill burden and an earlier switch from liquid to solid formulations. 
$\mathrm{LPV} / \mathrm{r}$ can be used daily in adults. In the Kaletra Once Daily Randomized Trial (KONCERT), 173 virally suppressed children weighing $>15 \mathrm{~kg}$ and on $\mathrm{LPV} / \mathrm{r}$ were randomised to daily $(n=86)$ or twice-daily $(n=87)$ dosing. Those given daily dosing were more likely to have low-level viraemia at week 48 ( $12 \mathrm{v}$. 7 children; $p=0.196$ ). The probability of viral rebound in the daily v. twice-daily group was 0.141 ( $90 \%$ confidence interval (CI) 0.09 - 0.217) v. 0.08 (90\% CI 0.044 - 0.145). In the greater majority the viraemia was suppressed without a dose change and new resistance rarely developed in either group. Participants preferred daily dosing. ${ }^{[25]}$

\section{Mycobacterium tuberculosis \\ co-infection}

TB remains a common problem in HIV-infected children. The incidence of TB disease is estimated at 23/100 child-years in HIVinfected children in SA. ${ }^{[26]}$ Access to ART remains an essential intervention to prevent $\mathrm{TB}$, and in children on therapy rates have declined substantially.

Co-treatment with rifampicin affects the metabolism of certain antiretroviral drugs, especially LPV/r, which may affect the virological outcomes. Limited data suggest that, unlike in adults, doubling the $\mathrm{LPV} / \mathrm{r}$ dosage does not achieve adequate PI bioavailability in young children on rifampicin. ${ }^{[27]} \mathrm{LPV} / \mathrm{r}$ 'super-boosted' with additional RTV, in order that the LPV and RTV have a 1:1 ratio, is the preferred strategy.

\section{Outcomes in African children on ART}

Despite access to ART, 7\% of children given ART die in the first year in a programmatic setting. ${ }^{[28]}$ In older children (mean age at starting 4.3 years), virological suppression rates of $96 \%$ by 12 months are reported from Soweto. ${ }^{[29]}$ In the P1060 study, approximately $80 \%$ of children on LPV/r achieved a viral load of $<400$ copies $/ \mathrm{mL}$ at week $24{ }^{[18]}$ In the International epidemiologic Databases to Evaluate AIDS (IeDEA) cohort, children starting ART at around 3.5 years of age had a $20 \%$ rate of virological failure after 3 years. ${ }^{[30]}$ The ARROW study confirmed this finding, with $83 \%$ of children on two NRTIs and an NNRTI having a viral load of $<400$ copies $/ \mathrm{mL}$ after a median of 3.7 years on therapy. ${ }^{[17]}$ Virological outcomes are equivalent to those in European or American children. ${ }^{[31]}$ The CHER study also assessed the possibility of treatment interruption. Here, gains were modest and there was no arm receiving early continuous ART for comparison. Therefore, we cannot recommend this strategy. ${ }^{[32]}$

\section{Failure of first-line regimens}

Poor adherence is the main reason for failure, but intolerance and drug interactions and/or drug toxicity are important contributors. Caregiver problems including poor physical and/or mental health, substance abuse, change in caregiver, multiple caregivers and family or household non-disclosure of HIV status are important contributors to failure. These factors should be explored in depth in failing children. As in adults, indications for resistance testing are driven by the availability of funds (Table 3 ). Children not taking any medication or who adhere poorly are unlikely to benefit from resistance testing. Furthermore, one may only detect resistance to current, not previous, medications. All resistance testing should be viewed in the context of full drug exposure history, including PMTCT. Children failing an initial regimen containing an NNRTI usually have resistance, but still have a powerful second regimen available. There are no studies in low-resource settings where delayed switching is common. However, adult data suggest that even with delayed switching after failing an NNRTI-based first line, an RTV-boosted PI with 2 NRTIs has a good outcome. Children failing LPV/r rarely have LPV/r resistance initially, unless previously given RTV monotherapy or TB therapy. ${ }^{[33,34]}$ In children failing $\mathrm{LPV} / \mathrm{r}$ as a first regimen, a resistance test and possibly LPV/r trough levels should be considered. We need more data on hair levels of LPV/r as a measure of long-term adherence before this strategy can be recommended. Resistance tests may not show PI resistance if the child was already switched to an NNRTIbased regimen or if ART was interrupted. These results should be interpreted cautiously and an experienced clinician should be consulted. Limited data suggest that African children on third-line ART regimens can do very well.

Table 3. Possible indications for resistance testing in children

\begin{tabular}{|c|c|}
\hline Scenario & Rationale for testing \\
\hline \multicolumn{2}{|l|}{ Transmission prevention failure } \\
\hline $\begin{array}{l}\text { Mothers failing first-line or second-line therapy } \\
\text { during pregnancy }\end{array}$ & $\begin{array}{l}\text { Resistance may include more than NNRTI resistance with possible NRTI and even PI } \\
\text { resistance transmitted to the infant }\end{array}$ \\
\hline Infants exposed to prolonged NVP during breastfeeding & Document resistance against second-generation NNRTI \\
\hline Infants failing dual or triple post-exposure prevention & Document resistance in the infant in order to plan therapy \\
\hline \multicolumn{2}{|l|}{ First-line failure } \\
\hline \multirow[t]{2}{*}{ First-line failure with NNRTI } & Document second-generation NNRTI resistance \\
\hline & Potentially prevents switching NRTI in selected patients \\
\hline First-line failure - boosted PI & $\begin{array}{l}\text { It is preferable that all such children are tested, as there may not be primary } \\
\text { mutations conferring PI resistance. Adherence should be documented }\end{array}$ \\
\hline $\begin{array}{l}\text { Ritonavir full-dose therapy and currently on a } \\
\text { boosted PI }\end{array}$ & Possible PI resistance \\
\hline $\begin{array}{l}\text { TB therapy during PI regimen, especially if } \\
\text { inappropriately boosted or not boosted }\end{array}$ & Possible PI resistance \\
\hline \multicolumn{2}{|l|}{ Second-line failure } \\
\hline All children & Planning a suppressive third line \\
\hline
\end{tabular}




\section{Drugs recently licensed for SA children}

Raltegravir (RGV), an integrase inhibitor, is registered in SA and is available as granules, $25 \mathrm{mg}$ and $100 \mathrm{mg}$ chewable tablets and $400 \mathrm{mg}$ film-coated tablets. These formulations are not interchangeable as they are not bioequivalent. RGV can be used in combination therapy from the age of 1 month and $3 \mathrm{~kg}$. Dosing is according to weight band and formulation specific. Currently, most SA children receiving RGV are on a third-line regimen with RTV-boosted darunavir (DRV). RGV efficacy was first reported in treatment-experienced children and youth in the P1066 study. ${ }^{[17]}$ However, it is a potential first-line option where there is a drug reaction or intolerance, provided the patient's virus is fully susceptible to the other two drugs in the regimen. Its dosing with rifampicin-based TB therapy in children is being studied. RGV has a low resistance barrier and if patients fail this drug it should be discontinued to prevent resistance to the second-generation integrase inhibitor dolutegravir (DTG). DTG has only recently been studied in children.

Atazanavir (ATZ), a newer PI, is a first-line drug for children $>6$ years old, adolescents and adults in the USA. Dosing is according to weight bands, beginning at $15 \mathrm{~kg}$. RTV boosting is mandatory until the age of 13 years, with the dose remaining the same across weight bands. ATZ can be given daily. Currently, very few children are using ATZ owing to limited formulations available, but in older children who cannot tolerate LPV/r this drug may be considered. If such patients develop $\mathrm{TB}$, rifampicin must be replaced with rifabutin, which requires dose adjustment. We recommend that an experienced clinician be consulted in these cases. Many patients on ATZ experience indirect hyperbilirubinaemia, which causes social discomfort but does not necessitate a therapeutic change. ${ }^{[35]}$

Boosted DRV is one of the most durable PIs, with fewer sideeffects than LPV/r. Few PI-experienced children have more than one mutation, making it a useful option for third-line regimens and second line after failing LPV/r. Recent data on DRV in a once-daily regimen in ART-naive adolescents, support consideration in first-line therapy. ${ }^{[36]}$ DRV is approved for children $>6$ years of age with $300 \mathrm{mg}$, $150 \mathrm{mg}$ and $75 \mathrm{mg}$ tablets registered in SA. There is some concern about DRV in children $<3$ years of age, as infant rats experienced seizures and a high death rate when exposed to the drug. ${ }^{[37]}$

Etravirine (ETV), an NNRTI, is registered in SA. However, children who failed extended NVP prophylaxis or become infected through breastfeeding while their mothers received EFV often have a virus harbouring the Y181C mutation precluding the NNRTI. ${ }^{[38]}$ There are no data for rilpivirine in children. This NNRTI is unaffected by Y181C.

\section{Conclusion}

Children graduating from the PMTCT programmes are increasingly exposed to multiple medications, which pose therapeutic challenges. There is a need to move from early to very early diagnosis and ART initiation, with its own set of challenges. There is increasing access to newly licensed drugs for failing children with complex disease, but we still lack palatable fixed-dose combinations as first-line therapy.

\section{References}

1. World Health Organization (WHO). Consolidated Guidelines on the Use of Antiretroviral Drugs for Treating and Preventing HIV Infection: Recommendations for a Public Health Approach. Geneva: WHO Press, 2013.

2. South African Department of Health, South African National AIDS Council. The South African South African Department of Health, South African National AIDS Council
Antiretroviral Treatment Guidelines. Pretoria: SA Department of Health, 2013.

3. Newell ML, Coovadia H, Cortina-Borja M, et al. Mortality of infected and uninfected infants born to HIV-infected mothers in Africa: A pooled analysis. Lancet 2004;364:1236-1243. [http://dx.doi.
to to HIV-infected mothers in Africa:
org/10.1016/S0140-6736(04)17140-7]

4. Violari A, Cotton MF, Gibb DM, et al. Early antiretroviral therapy and mortality among HIV-infected . Violari A, Cotton MF, Gibb DM, et al. Early antiretroviral therapy and mortality among $\mathrm{H}$ -
infants. N Engl J Med 2008;359:2233-2244. [http://dx.doi.org/10.1056/NEJMoa0800971]

5. Laughton B, Cornell M, Grove D, et al. Early antiretroviral therapy improves neurodevelopmental 5. Laughton B, Cornell M, Grove D, et al. Early antiretroviral therapy improves neurodevelopmental
outcomes in infants. AIDS 2012;26:1685-1690. [http://dx.doi.org/10.1097/QAD.0b013e328355d0ce] 6. Innes S, Lazarus E, Otwombe K, et al. Early severe HIV disease precedes early antiretroviral therapy in 6. Innes S, Lazarus E, Otwombe K, et al. Early severe HIV disease precedes early antiretroviral therapy in
infants: Are we too late? J Int AIDS Soc 2014;11(17):18914. [http://dx.doi.org/10.7448/IAS.17.1.18914]
7. Bitnun A, Samson L, Chun TW, et al. Early initiation of combination antiretroviral therapy in HIV-infected newborns can achieve sustained virologic suppression with low frequency of $\mathrm{CD} 4+\mathrm{T}$ cells carrying HIV in peripheral blood. Clin Infect Dis 2014;59(7):1012-1019.

8. Persaud D, Gay H, Ziemniak C, et al. Absence of detectable HIV-1 viremia after treatment cessation in an infant. N Engl J Med 2013;369:1828-1835. [http://dx.doi.org/10.1056/NEJMoa1302976]

9. Siegfried N, Davies MA, Penazzato M, Muhe LM, Egger M. Optimal time for initiating antiretroviral therapy (ART) in HIV-infected, treatment-naive children aged 2 to 5 years old. Cochrane Database
the Syst Rev 2013;10:CD010309. [http://dx.doi.org/10.1002/14651858.CD010309.pub2]

10. Puthanakit T, Saphorn V, Ananworanich J, et al. Early versus deferred antiretroviral therapy for Puthanakit T, Saphorn V, Ananworanich I, et al. Early versus deferred antiretroviral therapy for
children older than 1 year infected with HIV (PREDICT): A multicentre, randomised, open-label trial. children older than 1 year infected with HIV (PREDICT): A multicentre, randomised,
Lancet Infect Dis 2012;12: 933-941. [http://dx.doi.org/10.1016/S1473-3099(12)70242-6]

11. Puthanakit T, Ananworanich J, Vonthanak S, et al. Cognitive function and neurodevelopmental Puthanakit T, Ananworanich J, Vonthanak S, et al. Cognitive function an in HIV-infected children older than 1 year of age randomized to early versus deferred
outcomes outcomes in HIV-infected children older than 1 year of age randomized
antiretroviral therapy: The PREDICT neurodevelopmental study. Pediatr Infect Dis J 2013;32: 501508. [http://dx.doi.org/10.1097/INF.0b013e31827fb19d]

12. Paediatric European Network for Treatment of AIDS (PENTA). Comparison of dual nucleosideanalogue reverse-transcriptase inhibitor regimens with and without nelfinavir in children with HIV-
1 who have not previously been treated: The PENTA 5 randomized trial. Lancet 2002;359:733-740.
[http://dx.doi.org/10.1016/S0140-6736(02)07874-1]

13. Technau KG, Lazarus E, Kuhn L, et al. Poor early virologic performance and durability of abacavir3. Technau KG, Lazarus E, Kuhn L, et al. Poor early virologic performance and durability
based first-line regimens for HIV-infected children. Pediatr Infect Dis J 2013;32:851-855.

14. Zanoni BC, Phungula T, Zanoni HM, France H, Feeney ME. Impact of tuberculosis cotreatment on Zanoni $\mathrm{BC}$, Phungula T, Zanoni HM, France H, Feeney ME. Impact of tuberculosis cotreatment on
viral suppression rates among HIV-positive children initiating HAART. AIDS 2011;25:49-55. [http:// viral suppression rates among HIV-positive ch
dx.doi.org/10.1097/QAD.0b013e32833f9e04]

15. Musime V, Kekitiinwa A, Mulenga V, et al. CHAPAS 3: A randomized trial comparing stavudine vs Musiime V, Kekitiinwa A, Mulenga V, et al. CHAPAS 3: A randomized trial comparing stavudine vs
zidovudine vs abacavir as NRTI backbone in NNRTI-based first line ART in 478 HIV-infected children zidovudine vs abacavir as NRTI backbone in NNRTI-based first line ART in $478 \mathrm{HIV-in}$
in Uganda and Zambia. Reviews in Antiviral Therapy and Infectious Diseases 2014;6.

in Uganda and Zambia. Reviews in Antiviral Therapy and Infectious Diseases 2014;6.
16. Mallal S, Nolan D, Witt C, et al. Association between presence of HLA-B*5701, HLA-DR7,

6. Mallal S, Nolan D, Witt C, et al. Association between presence of HLA-B ${ }^{*} 5701$, HLA-DR7,
and HLA-DQ3 and hypersensitivity to HIV-1 reverse-transcriptase inhibitor abacavir. Lancet and HLA-DQ3 and hypersensitivity to HIV-1 reverse-transcriptase inhi

17. Nahirya-Ntege P, Musiime V, Naidoo B, et al. on behalf of the ARROW trial team. Low incidence of abacavir hypersensitivity reaction among African children initiating antiretroviral therapy. Pediatr Infect Dis J 2011:30(6):535-537.

18. Palumbo P, Lindsey JC, Hughes MD, et al. Antiretroviral treatment for children with peripartum nevirapine exposure. N Engl J Med 2010;363:1510-1520. [http://dx.doi.org/10.1056/NEJMoa1000931] 9. PENPACT-1 (PENTA 9/PACTG 390) Study Team. First-line antiretroviral therapy with a protease inhibitor versus nonnucleoside reverse transcriptase inhibitor and switch at higher versus low
viral load in HIV-infected children: An open-label, randomised phase $2 / 3$ trial. Lancet Infect Dis viral load in HIV-infected children: An open-label, randomised ph
2011;11:273-283. [http://dx.doi.org/10.1016/S1473-3099(10)70313-3]

20. Kuhn L, Coovadia A, Strehlau R, et al. Switching children previously exposed to nevirapine to nevirapine-based treatment after initial suppression with a protease-inhibitor-based regimen: Longterm follow-up of a randomised, open-label trial. Lancet Infect Dis 2012;12(7):521-530. [http://dx.doi. org/10.1016/S1473-3099(12)70051-8]

21. Coovadia A. Virologic efficacy of efavirenz maintenance therapy in nevirapine prophylaxis-exposed children. 21st Conference on Retroviruses and Opportunistic Infections (CROI), 3 - 6 March 2014, Boston, USA. Oral abstract 73

22. Paediatric European Network for Treatment of AIDS (PENTA). Pharmacokinetic study of once-daily versus twice-daily abacavir and lamivudine in HIV type-1-infected children aged $3-<36$ months. Antivir Ther 2010;15(3):297-305. [http://dx.doi.org/10.3851/IMP1532]

23. Bergshoeff A, Burger D, Verweij C, et al. Plasma pharmacokinetics of once- versus twice-daily lamivudine and abacavir: Simplification of combination treatment in HIV-1-infected children (PENTA-13). Antivir Ther 2005;10(2):239-246.

24. Musiime V, Kendall L, Bakeera-Kitaka S, et al. Pharmacokinetics and acceptability of once- versus twice-daily lamivudine and abacavir in HIV type-1-infected Ugandan children in the ARROW Trial, Antivir Ther 2010;15(8):1115-1124. [http://dx.doi.org/10.3851/IMP1695]

25. Lyall H. Final results of Koncert: A randomised noninferiority trial of QD vs BD LPV/r dosing in children. 21st Conference on Retroviruses and Opportunistic Infections (CROI), 3 - 6 March 2014, Boston, USA. Oral abstract 74LB

26. Walters E, Cotton MF, Rabie H, Schaaf HS, Walters LO, Marais BJ. Clinical presentation and outcome of tuberculosis in human immunodeficiency virus infected children on anti-retroviral therapy. BMC Pediatr 2008; 8:1-12. [http://dx.doi.org/10.1186/1471-2431-8-1]

27. Mcllleron H, Ren Y, Nuttall J, et al. Lopinavir exposure is insufficient in children given double doses of lopinavir/ritonavir during rifampicin-based treatment for tuberculosis. Antivir Ther 2011:16:417-421. [http://dx.doi.org/10.3851/IMP1757]

28. Davies MA, May MA, Bolton Moore C, et al. Prognosis of children with HIV-1 infection starting antiretroviral therapy in Southern Africa. A collaborative analysis of treatment programs. Pediatr Infect Dis J 2014;33:608-616. [http://dx.doi.org/10.1097/INF.0000000000000214]

29. Meyers T, Yoteieng M, Kuhn L, et al. Antiretroviral therapy responses among children attending a large public clinic in Soweto, South Africa. Pediatr Infect Dis J 2011;30(11):974-979. [http://dx.doi org/10.1097/INF.0b013e31822539f6

30. Davies MA, Moultrie H, Eley B, et al. and International Epidemiologic Databases to Evaluate AIDS Southern Africa (IeDEA-SA) Collaboration. Virologic failure and second-line antiretroviral therapy in children in South Africa - the IeDEA Southern Africa collaboration. J Acquir Immune Defic Syndr 2011;56:270-278. [http://dx.doi.org/10.1097/QAI.0b013e3182060610]

31. Peacock-Villada E, Richardson BA, John-Stewart GC. Post-HAART outcomes in pediatric populations: Comparison of resource-limited and developed countries. Pediatrics 2011;127:e423-441. [http://dx.doi.org/10.1542/peds.2009-2701

32. Cotton MF, Violari A, Otwombe K, et al. Early time-limited antiretroviral therapy versus deferred therapy in South African infants infected with HIV: Results from the children with HIV early antiretroviral (CHER) randomised trial. Lancet 2013;382:1555-1563. [http://dx.doi.org/10.1016/S0140-6736(13)61409-9]

33. Van Zyl GU, van der Merwe L, Claassen M, et al. Protease inhibitor resistance in South African children with virologic failure. Pediatr Infect Dis J 2009;28:1125-1127.

34. Taylor BS, Hunt G, Abrams EJ, et al. Rapid development of antiretroviral drug resistance mutations in Taylor BS, Hunt G, Abrams EJ, et al. Rapid development of antiretroviral drug resistance mutations in
HIV-infected children less than two years of age initiating protease inhibitor-based therapy in South HIV-infected children less than two years of age initia.
Africa. AIDS Res Hum Retroviruses 2011;27:945-956.

35. O'Mara E, Randall D, Passarell J, Steinberg S, Grasela D. Population pharmacodynamic assessment of atazanavir exposure, uridine diphosphate-glucuronosyl transferase (UGT) 1A1 genotype and safety atazanavir exposure, uridine diphosphate-glucuronosyl transferase (UGT) IAl genotype and safety
in healthy subjects. 42nd Interscience Congress on Antimicrobial Agents and Chemotherapy, 27 - 30 in healthy subjects. 42nd Interscience Congress on Antim
September 2002, San Diego, Calif., USA. Abstract A-1253.

36. Flynn P, Komar S, Blanche S, et al. Efficacy and safety of darunavir/ritonavir at 48 weeks in treatmentFlynn P, Komar S, Blanche S, et al. Efficacy and safety of darunavir/ritonavir at 48 weeks in treatment-
naive, HIV-1-infected adolescents. Pediatr Infect Dis J 2014;33:940-945. [http://dx.doi.org/10.1097/ naïv, HIV-1-infected

37. US Food and Drug Administration. Prezista Drug Label. Clinical Review of Darunavir, 2012

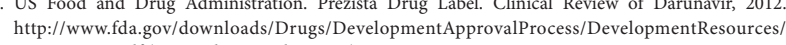
http://www.fda.gov/downloads/Drugs/Dev

38. Persaud D, Bedri A, Ziemniak C, et al. AIDS Res Hum Retroviruses 2011;27(8):823-829. [http://dx.doi. 8. Persaud D, Bedri A, Ziemniak
org/10.1089/AID.2010.0346] 